\title{
Depression and anxiety in individuals with amyotrophic lateral sclerosis: a systematic review
}

\author{
Depressão e ansiedade em pessoas com esclerose lateral amiotrófica: \\ uma revisão sistemática
}

Tatiana Lins Carvalho, ${ }^{1}$ Lilian Maria Sanguinett de Almeida, ${ }^{2}$ Camila Maria Araújo Lorega, ${ }^{2}$ Mirella Francyne Oliveira Barata, ${ }^{2}$ Maria Lúcia Brito Ferreira, ${ }^{3}$ Paulo Roberto de Brito-Marques, ${ }^{4}$ Carolina da Cunha Correia ${ }^{1}$

\begin{abstract}
Introduction: Studies assessing symptoms of depression and anxiety in individuals with amyotrophic lateral sclerosis (ALS) have reported contradictory results. The objective of this systematic review is to identify the prevalence of these mood disorders in the literature.

Methods: We searched the PubMed, HighWire, MEDLINE, SciELO, LILACS and ScienceDirect databases. Literature was selected for review in two stages, according to eligibility criteria. The first stage involved searching databases and checking titles and abstracts. The second step consisted of reading complete articles and excluding those that did not meet the inclusion criteria. The inclusion criteria were articles written in Portuguese, English or Spanish, published in the last five years and involving people with ALS diagnosed according to the El Escorial criteria.

Results: The database searches returned a total of 1,135 titles and abstracts and then 1,117 of these were excluded. Eighteen articles were selected for review. The 12-item Amyotrophic Lateral Sclerosis Depression Inventory (ADI-12) was the only instrument designed specifically to assess depression in ALS, but it was only used in three studies. No instruments specifically designed for anxiety in ALS were used. A large number of studies found presence and slight increase of anxiety disorders. There was considerable large variation in the results related to depressive disorders, ranging from moderate depression to an absence of symptoms.

Conclusions: Patients with ALS may exhibit symptoms of depression and anxiety at different levels, but there is a need for studies using specific instruments with larger samples in order to ascertain the prevalence of symptoms in ALS and the factors associated with it.
\end{abstract}

Keywords: Amyotrophic lateral sclerosis, anxiety, depression, incidence, prevalence.

\section{Resumo}

Introdução: Estudos avaliando sintomas depressivos e ansiosos em pessoas com esclerose lateral amiotrófica (ELA) têm apresentado resultados contraditórios. Esta revisão sistemática tem por objetivo identificar a prevalência desses transtornos do humor na literatura.

Métodos: A pesquisa foi feita nas bases de dados PubMed, $\mathrm{Hi}-$ ghWire, MEDLINE, SciELO, LILACS e ScienceDirect. A seleção dos estudos foi realizada em duas etapas de acordo com os critérios de elegibilidade. A primeira etapa envolveu pesquisa nas bases de dados e revisão de títulos e resumos. Na segunda etapa houve a leitura dos artigos completos e a exclusão dos que não preenchiam os critérios de inclusão. Os critérios de inclusão eram: publicação nos idiomas português, inglês ou espanhol, nos últimos 5 anos e envolvendo pessoas com ELA conforme o El Escorial.

Resultados: Um total de 1.135 títulos e resumos foram selecionados, mas 1.117 foram excluídos. Como resultado, 18 artigos foram incluídos na revisão. O Inventário de Depressão da Esclerose Lateral Amiotrófica com 12 itens (ADI-12) foi o único instrumento específico para avaliação da depressão na ELA utilizado, porém em apenas três estudos. Nenhum instrumento específico para ansiedade na ELA foi utilizado. Boa parte dos estudos apontaram presença e ligeiro aumento das desordens de ansiedade. Já para depressão houve grande diversidade de respostas, variando de depressão moderada à ausência de sintomas.

Conclusões: Pessoas com ELA podem apresentar sintomas depressivos e ansiosos em proporções diferentes, mas há a necessidade de estudos com instrumentos específicos e com amostras mais amplas para que se possa averiguar a prevalência das sintomatologias na ELA e os fatores associados a elas.

Descritores: Esclerose amiotrófica lateral, ansiedade, depressão, incidência, prevalência.

${ }^{1}$ Hospital Universitário Oswaldo Cruz, Universidade de Pernambuco (UPE), Recife, PE, Brazil. ${ }^{2}$ Universidade Federal de Pernambuco (UFPE), Recife, PE, Brazil. ${ }^{3}$ Centro de Referência para Atenção ao Paciente Portador de Doença Desmielinizante (CRAPPDD), Hospital da Restauração (HR), Recife, PE, Brazil. ${ }^{4}$ Unidade de Neurologia Comportamental, Departamento de Neurologia, Faculdade de Ciências Médicas, UPE, Recife, PE, Brazil.

Financial support: none.

Submitted May 25 2015, accepted for publication Aug 19 2015. No conflicts of interest declared concerning the publication of this article.

Suggested citation: Carvalho TL, Almeida LM, Lorega CM, Barata MF, Ferreira ML, Brito-Marques PR, et al. Depression and anxiety in individuals with amyotrophic lateral sclerosis: a systematic review. Trends Psychiatry Psychother. 2016;38(1):1-5. http://dx.doi.org/10.1590/2237-6089-2015-0030 


\section{Introduction}

It is expected that patients with amyotrophic lateral sclerosis (ALS) will exhibit a high incidence of depression and significant reductions in quality of life. However, studies confirm that there is no direct correlation between progression of the disease and development of depression, anxiety or emotional stress. Perception of physical and functional losses related to the condition has often been shown to cause depressive symptoms during diagnosis, but depression itself has not been clinically proven. ${ }^{1,2}$

Studies of the relationship between functional impairment and psychological suffering have reported inconsistent results. While a number of studies have observed positive associations between the seriousness of functional impairment and psychological affliction, others have reported negative correlations between these two variables, finding that people with ALS who were relatively healthy and able to lead normal lives were suffering from deeper depression than those who were physically ill. ${ }^{3}$

Anguish, fear and concern about the future are often more recurrent in these patients. The way in which patients deal with this condition is related to their social context, in terms of family support and the network of care available to them. ${ }^{1}$ This article describes a systematic review carried out to identify whether people with ALS develop symptoms of depression and anxiety when faced with the limiting conditions resulting from the disease.

\section{Methods}

\section{Databases, search terms and eligibility criteria}

Studies were identified using the PubMed, HighWire, MEDLINE, SciELO, LILACS and ScienceDirect databases during July 2014. The following search terms were used: Amyotrophic Lateral Sclerosis, Depression, Anxiety, Prevalence and Incidence, in different combinations. Inclusion criteria were articles written in Portuguese, English and Spanish, published in the last five years on patients with ALS diagnosed according to the El Escorial criteria. Review or systematic review articles and those involving validation studies or other mood disorders were excluded.

\section{Study selection process}

In the first stage of selection three researchers used the search terms to search the databases, assessing titles and abstracts in accordance with eligibility criteria. The abstracts selected then underwent a second stage, in which two other independent researchers reviewed the full texts of articles and by consensus excluded those that did not meet the criteria. Data on sample size and characteristics, time, study type, instruments administered and primary outcomes obtained were extracted from the articles identified as eligible.

\section{Results}

The flowchart in Figure 1 illustrates the steps taken to select studies for review. A total of 1,135 titles and abstracts were selected in the first stage and then 1,083 of these were excluded because they did not meet the eligibility criteria or were duplicated. Table 1 lists the combinations of search terms used in the first stage.

After analysis of the full texts of articles (second stage), 34 of the 52 that had initially been selected on the basis of their titles and abstracts were excluded. They were excluded because: the primary topic of the studies considered the presence of depression and anxiety in patients with ALS as secondary; they only studied carers; they were interventions; the studies did not involve humans; or diagnosis of ALS was based on Airlie-House criteria.

Data from the 18 articles included in this systematic review are summarized in Table 2.

A number of limitations were listed by the authors of the studies that met the eligibility criteria. These included the following: small sample size; convenience sample; some patients' inability to respond to questionnaires, requiring them to be filled out by someone else; absence of a control group; use of antidepressants; nonspecific tests for depression in ALS; patients who attended multidisciplinary clinics were more motivated; sample biased by exclusion of depressed patients; and the possibility that ALS symptoms mask depression symptoms.

\section{Discussion}

This systematic review found a predominance of articles assessing depression, with only 7 out of 18 articles investigating anxiety. This may have been a result of the increasing incidence of depressive disorders in the population and because it is considered one of the most debilitating diseases in the world. ${ }^{20}$

The most widely used tools listed in Table 2 are the Hospital Anxiety and Depression Scale (HADS), Beck's Depression Inventory (BDI), the Structured Clinical 
Interview for DSM (SCID) and the Diagnostic and Statistical Manual of Mental Disorders, fourth edition (DSM-IV). The 12-item Amyotrophic Lateral Sclerosis Depression Inventory (ADI-12), which is an instrument specifically designed to detect depression symptoms in ALS, was administered in just three studies, leading us to question whether the non-selection of this instrument was because it has not been validated in other countries. It is important to emphasize that using nonspecific instruments may result in inadequate responses, since some studies emphasize the physical symptoms of depression, such as questions involving slowness in performing activities, which are also among the limiting features of ALS progression.
Six of the 18 articles exclusively assessed ALS patients, while the remaining studies made comparisons with control groups. Given the fact that it is considered rare, studies involving this disease generally do not investigate large samples. Eleven of the articles selected had sample sizes of 40 patients with ALS or fewer and their findings may not be representative of the general population.

A significant number of the articles that assessed anxiety disorders reported slight increase in these disorders. In contrast, there was a large variation in the results related to depressive disorders, ranging from moderate depression to an absence of symptoms. Studies suggest that both depression and anxiety should be investigated in patients, since they may exhibit some type of association..$^{4,5,21}$

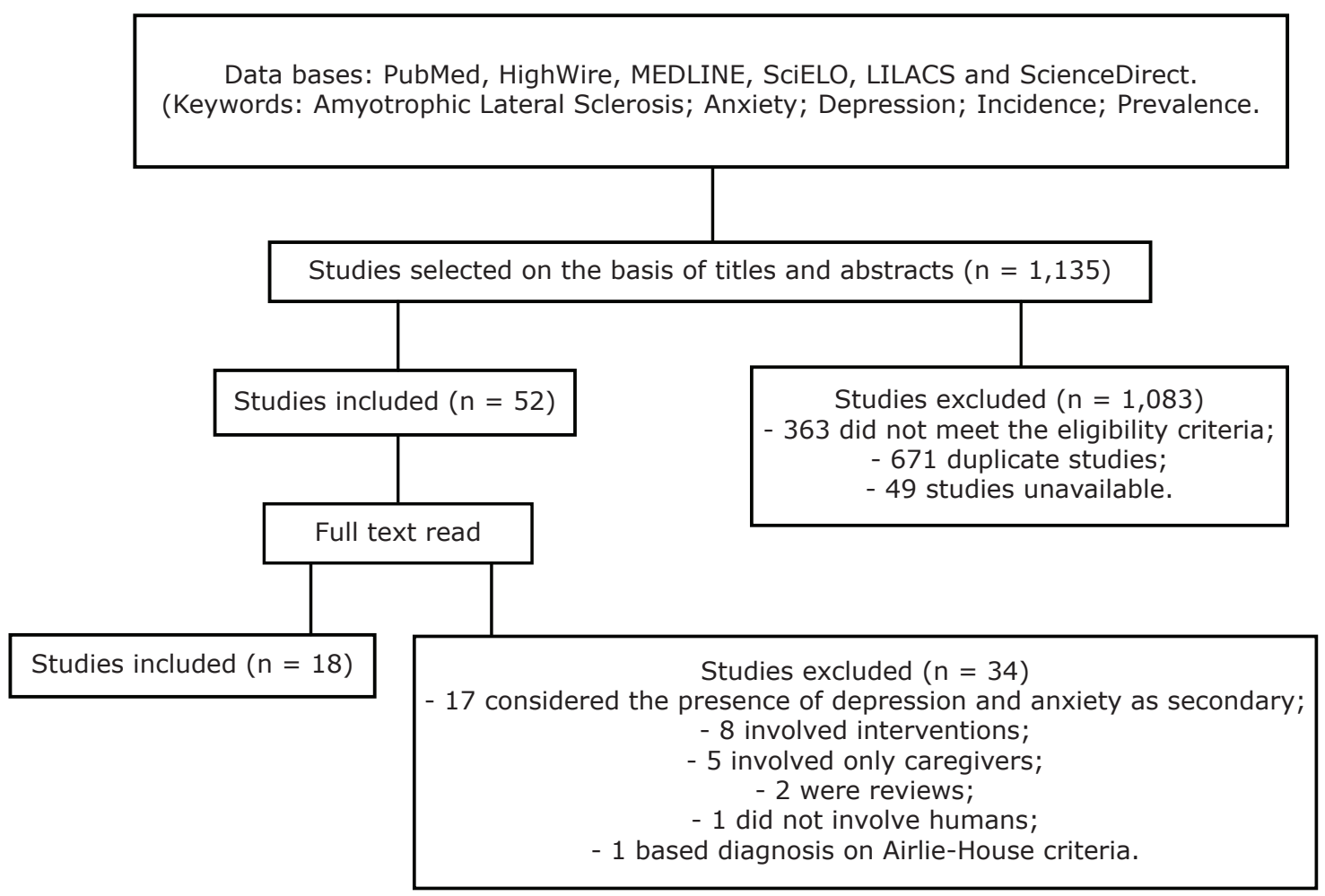

Figure 1 - Flowchart illustrating search and selection of studies that included assessment of depression and anxiety in people with amyotrophic lateral sclerosis.

Table 1 - Results of the first stage of the systematic review

\begin{tabular}{|c|c|c|c|c|}
\hline \multirow[t]{2}{*}{ Combination of search terms } & \multicolumn{3}{|c|}{ Total no. abstracts found } & \multirow[t]{2}{*}{ Total excluded } \\
\hline & English & Portuguese & Spanish & \\
\hline [Amyotrophic lateral sclerosis and Prevalence and Depression] & 41 & 34 & 0 & 59 \\
\hline [Amyotrophic lateral sclerosis and Prevalence and Anxiety] & 44 & 7 & 6 & 50 \\
\hline [Amyotrophic lateral sclerosis and Incidence and Depression] & 79 & 29 & 30 & 136 \\
\hline [Amyotrophic lateral sclerosis and Incidence and Anxiety] & 32 & 5 & 5 & 42 \\
\hline [Amyotrophic lateral sclerosis and Depression] & 343 & 183 & 120 & 625 \\
\hline [Amyotrophic lateral sclerosis and Anxiety] & 126 & 38 & 13 & 171 \\
\hline
\end{tabular}


Table 2 - Data from studies included in the systematic review

\begin{tabular}{|c|c|}
\hline Identification & $\begin{array}{c}\text { Methodology } \\
\text { (study type, participants, instruments }\end{array}$ \\
\hline Atassi et al. ${ }^{4}$ & $\begin{array}{l}\text { Cross-sectional study. } \\
127 \text { people with ALS. } \\
\text { ADI-12. }\end{array}$ \\
\hline Chen et al. ${ }^{5}$ & $\begin{array}{l}\text { Cross-sectional study. } \\
93 \text { people with ALS and } 93 \text { caregivers. } \\
\text { DSM-IV, Hamilton Rating Scale for } \\
\text { depression and anxiety. }\end{array}$ \\
\hline Chio et al. ${ }^{6}$ & $\begin{array}{c}\text { Cross-sectional study. } \\
70 \text { pairs of ALS patients and their } \\
\text { caregivers. } \\
\text { ZDS. }\end{array}$ \\
\hline Cuddy et al. ${ }^{7}$ & $\begin{array}{l}\text { Cross-sectional study. } \\
19 \text { patients with ALS and } 19 \text { healthy } \\
\text { controls. } \\
\text { HADSd, ELQ. }\end{array}$ \\
\hline Ferentinos et al. ${ }^{8}$ & $\begin{array}{c}\text { Cross-sectional study. } \\
37 \text { patients with ALS. } \\
\text { SCID-IV, HADS, ADI-12, CES-D, BDI. }\end{array}$ \\
\hline
\end{tabular}

Huey et al. ${ }^{9}$

Jelsone-Swain et al. ${ }^{10}$

Jakobsson

Larsson et al. ${ }^{11}$

Lillo et al. ${ }^{12}$

Lulé et al. ${ }^{13}$

Lulé et al. ${ }^{14}$

Marconi et al. ${ }^{15}$

Montel et al. ${ }^{16}$

Oh et al. ${ }^{3}$

Olsson et al. ${ }^{17}$

Olsson Ozanne et al. ${ }^{18}$
Cross-sectional study.

13 patients with ALS and 19 with PLS. SCID.

Cross-sectional study.

22 patients with ALS and 17 healthy people.

GDS, BDI.

Prospective, longitudinal and descriptive study.

33 patients with ALS. HADS.

Cross-sectional study.

92 patients and 81 caregivers. DASS.

Cross-sectional study. 30 patients with ALS; 29 people with cancer; 29 healthy controls.

$$
\text { BDI. }
$$

Cross-sectional study. 89 ALS patients, 188 healthy people and 86 primary caregivers. ADI-12.

Cross-sectional study. 10 ALS patients and 10 caregivers. DSM-IV, SCID II, HADS.

Cohort study.

30 people with ALS. DSM-IV-TR.

Cross-sectional study. 62 ALS patients. BDI.

Cross-sectional study. 35 patients with ALS and 35 relatives. HADS.

Descriptive study. 35 ALS patients paired with family members.
Main results

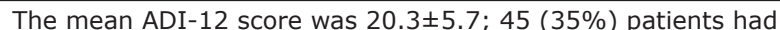
depression and $82(65 \%)$ did not; $29 \%$ had mild depression and $6 \%$ severe depression; men were more likely to have depression than women $(p=0.01)$.

Fifty-three patients diagnosed with depression (mild $=33$; major $=20) ; 23$ caregivers with depression ( mild $=18$; major $=5$ ). Depression and anxiety in patients and caregivers were closely associated with each other; depression and anxiety disorders are more common in Chinese patients with ALS (57 and 67\% respectively) than in their caregivers (24 and 36\% respectively). ZDS $=42.1 \pm 9.6$; nine $(12.9 \%)$ patients had mild depression and six $(8.6 \%)$ had moderate depression; ZDS average $=39.1 \pm 7.6$; eight $(11.4 \%)$ caregivers had mild depression.

There was no significant difference in ELQ scores (z score $=-0.5, \mathrm{p}=0.62$ ).

People with ALS had higher HADSd scores than controls, but this difference was not significant and mean scores for both groups were in the normal range; there was no association between HADSd scores and emotional processing in either group.

Fourteen (37.8\%) patients had major depressive disorder according to the SCID-IV.

All four depression severity scores were highly correlated with each other $(r>0.6)$, except for the ADI-BDI correlation (0.423).

Major depressive episodes: eight (21.6\%) SCID-IV; six (16.7\%)

with HADSd $\geq 11$. 6 (16.2\%) with ADI $\geq 29$; nine (25\%) with CES-D $\geq 24$; nine (24.3\%) with a BDI-I score $\geq 17$.

Depressive disorders were the most commonly observed psychiatric disorders in ALS; prevalence $=46 \%$.

Mean GDS scores were higher in patients with ALS 2.32 \pm 1.97 than in healthy controls $1.07 \pm 1.16$, but the scores did not reach the threshold for depression.

Fifteen patients scored 8 or more on HADSa at time point 1 and five at time point 2. Four patients scored 8 or more on HADSd at time point 1 and six at time point 2 . There were no changes in mean anxiety and depression scores from time point 1 to time point 2 .

More than $70 \%$ of the ALS patients did not reach the threshold for depression, but $21 \%$ had moderate to very severe depression; $18.5 \%$ of patients had moderate to severe anxiety.

There was a significant difference between groups for depression: ALS group $=12.90 \pm 4.92 ;$ cancer patients $=12.10 \pm 8.39 ;$ controls $=6.24 \pm 4.02 ; \mathrm{F}=10.51, \mathrm{df}=87, \mathrm{p}<0.01$. There was also $\mathrm{a}$ significant difference between ALS and controls ( $d f=57, p<0.01$ ). Both groups of patients had mild to moderate depression.

Mean depression scores were significantly different between groups (ANOVA df $=439, F=72.71, p<0.001$ ).

Patients' depression increased slightly with speed of disease progression (Pearson correlation $r=0.28, p=0.02$ ).

There was a high level of anxiety in patients (11.2 \pm 2.1$)$ and caregivers $(11.7 \pm 2.0)$. Patients' scores indicated borderline depression (10.4 \pm 2.5$)$ and caregivers' scores were equivalent to

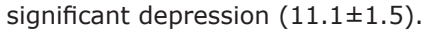

Only $27 \%$ of the sample suffered from psychological distress at T1; there was no significant correlation between disease severity and psychological suffering.

Mean BDI score: $24.5 \pm 12.88 ; 54.8 \%$ had depressive symptoms.

There was no change over time in the HADS, but the average anxiety was slightly increased in the first two visits; for depression, the scale was normal for the caregivers who were partners.

There were no differences in HADS scores between patients and their families; patients and relatives had poorer ratings on HADS than the general population. 


\begin{tabular}{|c|c|c|}
\hline Pizzimenti et al. ${ }^{2}$ & $\begin{array}{c}\text { Cross-sectional study. } \\
36 \text { patients. } \\
\text { SDS. }\end{array}$ & $\begin{array}{l}\text { SDS score: } 50 \text { or above, depression (one patient); average of the } \\
\text { SDS scores: } 35.6 \pm 8.1 \text {. } \\
\text { Sixteen patients self-reported severe depressive symptoms, but } \\
\text { remained in the not-depressed range. }\end{array}$ \\
\hline Taylor et al. ${ }^{19}$ & $\begin{array}{l}\text { Cross-sectional study. } \\
51 \text { ALS patients and } 39 \text { with PLS or } \\
\text { progressive muscular atrophy. } \\
\text { BDI-II, MDI, HADS. }\end{array}$ & $\begin{array}{l}\text { Scores for the ALS group were as follows: } 15: 59(7.84) \text { on the BDI- } \\
\text { II; } 13: 07(7.62) \text { on the MDI; and } 6.61(3.96) \text { on the HADSd. } \\
\text { There were no differences between ALS and non-ALS groups in } \\
\text { scores for MDI }\left(F_{1,77}=0.511, P=0.477\right), \operatorname{HADSd}\left(\mathrm{F}_{1,77}=1.369, \mathrm{P}=\right. \\
0.246) \text { or BDI-II }\left(\mathrm{F}_{1,77}=00: 14, \mathrm{P}=0.95\right) \text {. } \\
\text { The } \mathrm{X}^{2} \text { test revealed no relationships between groups and depression } \\
\text { ratings for any of the instruments. }\end{array}$ \\
\hline
\end{tabular}

ADI-12 = 12-item Amyotrophic Lateral Sclerosis Depression Inventory; ALS = amyotrophic lateral sclerosis; ANOVA = analysis of variance; $B D I=$ Beck's Depression Inventory; CES-D = Center for Epidemiologic Studies Depression Scale; DASS = Depression, Anxiety and Stress Scale; $\mathrm{df}=$ degrees of freedom; DSM-IV = Diagnostic and Statistical Manual of Mental Disorders, fourth edition; DSM-IV-TR = Diagnostic and Statistical Manual of Mental Disorders, fourth edition, text revision; ELQ = Emotional Liability Questionnaire; GDS = Geriatric Depression Scale; HADS = Hospital Anxiety and Depression Scale; HADSa = Hospital Anxiety and Depression Scale - Anxiety; HADSd = Hospital Anxiety and Depression Scale - Depression; MDI = Major Depression Inventory; PLS = primary lateral sclerosis; SDS = Zung Self-Rating Depression Scale; SCID-IV = Structured Clinical Interview for DSM-IV; ZDS = Zung Depression Scale.

The studies showed that factors such as age, ${ }^{4,11,18}$ use of Riluzole, ${ }^{4,19}$ time from onset of symptoms to diagnosis, ${ }^{4}$ disease duration ${ }^{4,5,16}$ and physical disability ${ }^{3,5}$ were not correlated with depression or anxiety. However, future studies should investigate these mood disorders and the factors that could be involved in this association using larger samples and disease-specific instruments. Limitations of this review were: no articles were identified that administered a specific instrument for anxiety in ALS and few used disease-specific depression instruments; and the reference lists of studies not included were not reviewed.

\section{References}

1. Mora JS, Salas T, Fajardo ML, Iváñez L, Rodríguez-Santos F. Self perceived emotional functioning of spanish patients with amyotrophic lateral sclerosis: a longitudinal study. Front Psychol. 2013;3:609.

2. Pizzimenti A, Aragona M, Onesti E, Inghilleri M. Depression, pain and quality of life in patients with amyotrophic lateral sclerosis: a cross-sectional study. Funct Neurol. 2013;28:115-9.

3. Oh H, Sin MK, Schepp KG, Choi-Kwon S. Depressive symptoms and functional impairment among amyotrophic lateral sclerosis patients in South Korea. Rehabil Nurs. 2012;37:136-44.

4. Atassi N, Cook A, Pineda C, Yerramilli-Rao P, Pulley D, Cudkowicz $M$. Depression in amyotrophic lateral sclerosis. Amyotroph Lateral Scler. 2011;12:109-12.

5. Chen D, Guo X, Zheng Z, Wei Q, Song W, Cao B, et al. Depression and anxiety in amyotrophic lateral sclerosis: correlations between the distress of patients and caregivers. Muscle Nerve. 2015;51:353-7.

6. Chio A, Vignola A, Mastro E, Giudici AD, Iazzolino B, Calvo A, et al. Neurobehavioral symptoms in ALS are negatively related to caregivers' burden and quality of life. Eur J Neurol. 2010;17:1298303.

7. Cuddy M, Papps BJ, Thambisetty M, Leigh PN, Goldstein LH. Processing and memory for emotional and neutral material in amyotrophic lateral sclerosis. Amyotroph Lateral Scler. 2012;13:592-8

8. Ferentinos $P$, Paparrigopoulos $T$, Rentzos M, Zouvelou V, Alexakis $\mathrm{T}$, Evdokimidis I. Prevalence of major depression in ALS: comparison of a semi-structured interview and four self-report measures. Amyotroph Lateral Scler. 2011;12:297-302.
9. Huey ED, Koppel J, Armstrong N, Grafman J, Floeter MK. A pilot study of the prevalence of psychiatric disorders in PLS and ALS. Amyotroph Lateral Scler. 2010;11:293-7.

10. Jelsone-Swain $L$, Persad $C$, Votruba $K L$, Weisenbach $S L$, Johnson $T$, Gruis KL, et al. The Relationship between Depressive Symptoms, Disease State, and Cognition in Amyotrophic Lateral Sclerosis. Front Psychol. 2012;3:542.

11. Jakobsson Larsson B, Nordin K, Askmark H, Nygren I. Coping strategies among patients with newly diagnosed amyotrophic lateral sclerosis. J Clin Nurs. 2014;23:3148-55.

12. Lillo $\mathrm{P}$, Mioshi $E$, Zoing MC, Kiernan MC, Hodges JR. How common are behavioural changes in amyotrophic lateral sclerosis? Amyotroph Lateral Scler. 2011;12:45-51.

13. Lulé $D$, Pauli S, Altintas $E$, Singer U, Merk T, Uttner I, et al. Emotional adjustment in amyotrophic lateral sclerosis (ALS). J Neurol. 2012;259:334-41.

14. Lulé D, Ehlich B, Lang D, Sorg S, Heimrath J, Küber A, et al. Quality of life in fatal disease: the flawed judgement of the social environment. J Neurol. 2013;260:2836-43.

15. Marconi A, Meloni G, Fossati F, Lunetta C, Bastianello S, Melazzini $M$, et al. Aggressiveness, sexuality, and obsessiveness in late stages of ALS patients and their effects on caregivers. Amyotroph Lateral Scler. 2012;13:452-8.

16. Montel S, Albertini L, Desnuelle C, Spitz E. Evolution of quality of life, mental health, and coping strategies in amyotrophic lateral sclerosis: a pilot study. J Palliat Med. 2012;15:1181-4.

17. Olsson AG, Markhede I, Strang S, Persson LI. Differences in quality of life modalities give rise to needs of individual support in patients with ALS and their next of kin. Palliat Support Care. 2010;8:75-82.

18. Olsson Ozanne AG, Strang S, Persson LI. Quality of life, anxiety and depression in ALS patients and their next of kin. J Clin Nurs. 2010;20:283-91.

19. Taylor L, Wicks P, Leigh PN, Goldstein LH. Prevalence of depression in amyotrophic lateral sclerosis and other motor disorders. Eur J Neurol. 2010;17:1047-53.

20. Brandt WA, Loew T, von Heymann F, Stadtmüller G, Tischinger $M$, Strom $F$, et al. How does the ICD-10 symptom rating (ISR) with four items assess depression compared to the BDI-II? A validation study. J Affect Disord. 2015;173:143-5.

21. Lacerda-Pinheiro SF, Pinheiro Junior RF, Pereira de Lima MA, Lima da Silva CG, Vieira dos Santos Mdo S, Teixeira Junior AG, et al. Are there depression and anxiety genetic markers and mutations? A systematic review. J Affect Disord. 2014;168:387-98.

\section{Correspondence:}

Tatiana Lins Carvalho

Rua Antônio de Castro, 150/601, Casa Amarela

52070-080 - Recife, PE - Brazil

E-mail: tatiana.Icarvalho@gmail.com 